\title{
JaVier San MARTín y TOMÁs Domingo MORATALLa (EDS.) \\ PERSPECTIVAS SOBRE LA VIDA humana: \\ CUERPO, MENTE, GÉNERO, PERSONA. \\ MADRID, Biblioteca NueVA, 2011, 389 PP.
}

por Sonia E. Rodríguez García

Tras la publicación de Las dimensiones de la vida humana. Ortega, Zubiri, Marías y Laín Entralgo (Madrid, Biblioteca Nueva, 2010) y de La imagen del ser humano. Historia, literatura y hermenéutica (Madrid, Biblioteca Nueva, 2011), llega hasta nosotros Perspectivas sobre la vida humana, libro con el que se cierra esta trilogía que tuvo su origen en el VIII Congreso de Antropología Filosófica organizado por la Sociedad Hispánica de Antropología Filosófica (S.H.A.F.) en el año 2008.

En esta tercera entrega, los editores, Javier San Martín y Tomás Domingo Moratalla, recopilan una serie de artículos en torno a seis aspectos esenciales de la vida humana, cuestiones todas ellas paradigmáticas de la antropología filosófica. Nueva muestra, por lo tanto, de la actualidad, vigencia y relevancia de esta disciplina dentro del ámbito de conocimiento filosófico y de las ciencias humanas y sociales. Claro ejemplo de ello es el sólido hilo conductor de cada una de las partes del libro, a través de las cuales queda justificada la diversidad de los estudios e investigaciones presentados, al mismo tiempo que se muestra el carácter interdisciplinar de la antropología filosófica y se profundiza en sus vínculos con las ciencias naturales, las neurociencias, la psicología, la medicina y la bioética, la sociología y las ciencias políticas. 
La primera parte, «Vida humana y cuidado de la tierra», centra su atención en la condición del ser humano como cuerpo que habita en un mundo del que inevitablemente depende y con el cual debe adquirir un compromiso de cuidado y respeto. De este modo, se plantean las bases filosóficas de la cuestión ecológica en el siglo XXI (Octavi Piulats), las características esenciales que debe cumplir una "filosofía ecológica" o "ecosofía" (José Manuel Arnáiz), el sentido ecológicoespiritual en el mito Yvy-Mara ey del pueblo Tupí y la influencia en aquel de las culturas de los Omaguas, Chachapoyas e Incas (Juan Carlos Ochoa), la radical importancia de una educación ambiental que incida en el cuidado ético de la tierra y del mundo (Enmanuel Oliveira), la necesidad de una nueva antropología filosófica abierta al campo de la ecología (Patricia Homs Ramírez), el análisis del pensamiento naturalista como filosofía social y propuesta ética (Josep María Roselló), la némesis ecológica como expresión natural de una crisis cultural, consecuencia de una expropiación del ser humano de su lugar en la naturaleza (Valerià Martínez), y la recuperación de una antropología y cosmología, siguiendo a Pannikar, que revele la
Gran Cadena del Ser en donde Mundo y Seres puedan recuperar su lugar original (Xavier Serra).

La segunda parte, «El problema de la mente y el cuerpo y las neurociencias», retoma uno de los problemas más propios y acuciantes de la antropología filosófica: el dualismo mente-cuerpo. A este respecto y a través de la respuesta que Kant ofrece a Sömmerring, podemos comprender como la cuestión del alma no es una cuestión metafísica, sino fenomenológica y hermenéutica, pues remite a un determinado modo de comprensión e interpretación de nosotros mismos (Jesús González). Ahora bien, en la actualidad, el problema mente-cuerpo encuentra un nuevo reto en los avances científicos de la neurociencia, tema este que puede ser abordado a través de una relectura de Damásio con el fin de construir una imagen completa del ser humano (Óscar Barroso); sin olvidar, en ningún caso, que la pretensión de las neurociencias de reducir la toma de decisiones morales a una serie de procesos cognitivos no agota la explicación de todos los aspectos morales imbricados en el ser humano y que, en último término, esta pretensión puede constituir un aten- 
tado contra la libertad y la responsabilidad moral (Alicia Rodríguez).

La tercera parte del libro, «La afectividad: emociones y sentimientos», supone la defensa de la afectividad como aspecto primordial de la vida humana, dimensión que la tradición ha tildado injustamente de inferior respecto a la dimensión racional del ser humano. Por ello, es necesario liberarse de falsos prejuicios y entender las emociones como estrategias biológicas sin las que no podríamos sobrevivir ni como individuos particulares ni como seres sociales (Ma Luz Pintos), así como entenderlas en su función social para el desarrollo de la persona en el mundo (Elsa Muro). A este objetivo se encamina toda una serie de estudios que ponen de manifiesto la relevancia de determinados sentimientos en nuestra vida, como el deseo (Inmaculada Hoyos), el estrés emocional (María Leira) o el dolor (Francisco Escandón). Estudios a los que debemos añadir las reflexiones sobre el significado pragmático del gusto y su analogía con la moral (Manuel Sánchez), y la consideración de los valores como aceptación consciente, generación del propio yo y autorrealización (Josefina Rojo).

La cuarta parte, «Tecnologías biomédicas y nuevos humanismos», investiga y profundiza en la estrecha relación que deben mantener bioética y antropología filosófica. Para ello será necesario preguntarse, en primer lugar, qué antropología para qué bioética, pues sólo si éstas permanecen abiertas a la actitud hermenéutica y al diálogo interdisciplinar podrán forjar la tan necesaria y mutua interrelación (Tomás Domingo). Además, bioética y antropología filosófica deben atender a los nuevos avances médicos y tecnológicos con el fin de determinar los difusos -y más que peligrososlímites que en ningún caso deberían ser traspasados en nuestra búsqueda de la "perfección" humana (Lydia Feito). De igual modo, la bioética debe replantearse los límites de lo terapéutico, tarea a la que la antropología filosófica puede prestar gran ayuda, pues los avances científicos y tecnológicos plantean cuestiones concernientes a la reflexión filosófica (Juan Masiá).

La quinta parte de este libro, «El sexo y el género en la antropología filosófica», aborda una de las temáticas de mayor actualidad, la cuestión del género, con la intención de desenmascarar mitos, prejuicios y excesos del tradicional pensamiento hegemónico. Para comprender la génesis de este pensamiento puede 
ser útil recordar la imagen que la sociedad burguesa formó de la mujer y de la sexualidad femenina (Gemma Vicente) o explorar los paralelismos existentes entre el discurso actual de estudiosos del Islam y pensadores ilustrados del siglo XXI, que, paradójicamente, apuestan por la "igualdad universal del ser humano" al tiempo que mantienen una doble ciudadanía: universal y política para el hombre, y social para la mujer (Elena Hernández). En esta misma línea, diferentes investigadores han coincidido en recuperar la voz de tan reconocidas filósofas como Beauvoir, Witting y, muy especialmente, Butler, con el fin de descubrir el género como una construcción cultural y no como algo que nos sea naturalmente dado (Elvira Burgos), considerar el efecto preformativo de las normas de género expuestas por Judith Butler (Lola Fernández) $y$, siguiendo a esta misma filósofa, entender el sexo y el género como aspectos reducibles a una cuestión de liberación y voluntad (Juan de Dios). El objetivo común a todas estas investigaciones será superar los planteamientos existencialistas de "lo femenino" y "lo masculino", y despertar, con María Zambrano, a la verdadera naturaleza del ser humano como ser social que tiene derecho a ser él/ella mismo/a (Mercedes Gómez). Relacionada con la cuestión del género se afronta el tema de la sexualidad, al que, en esta ocasión, nos podemos acercar a través de la obra de Didier Eribon para desentrañar las principales formas de insulto en el discurso homófobo (Geoffroy Huard).

Por último, la sexta parte del libro, «La dimensión jurídico-social de la vida humana», hace hincapié en el ser humano como sujeto de derechos. Los estudios aquí recogidos nos aproximan a esta perspectiva a través de la reflexión sobre la familia, la unión matrimonial y las diferentes versiones de la libertad (Aranzazú Novales); la articulación entre identidad y política en el ámbito de los derechos humanos, que nos lleva a replantear la condición humana a partir de la concepción urbana contemporánea (Paula Cristina Pereira); el análisis, siguiendo a Marcuse, del estado de bienestar como una dimensión represiva, que utiliza la técnica y la productividad para dominar al individuo a través de un estilo de vida acomodaticio (María de las Viñas Rosillo); la consideración de la vida como "narración del florecimiento individual", en palabras de McIntyre, 
que se desarrolla en el marco de unas normas y prácticas sociales (David Lorenzo); la definición de la experiencia jurídica a través de un análisis fenomenológico que comprenda los principios del derecho (Felice Masi); la valoración de nuestro comportamiento dentro de un mercado capitalista para la consecución de una sociedad cívica y responsable en el ejercicio de los derechos humanos (Ainara Sánchez); el desenmascaramiento del derecho como práctica social del poder y de la función legitimadora de las instituciones políticas y jurídicas ( $\mathrm{M}^{\mathrm{a}}$ del Carmen Schilardi); y, finalmente, la interpretación de la intersubjetividad como un momento de la vida humana dentro de la totalidad social y cultural (Eduardo Álvarez).

Perspectivas de la vida humana es el libro que, dentro de esta trilogía, nos acerca de forma paradigmática a los problemas actuales de la antropología filosófica. Estamos, pues, ante un libro que se configura como punto de encuentro de numerosos estudiosos e investigadores; un libro a través del cual se establece un enriquecedor diálogo interdisciplinar que merece toda nuestra consideración. 